\title{
Radiation Enhances the Efficacy of Antitumor Immunotherapy with an Immunocomplex of Interleukin-2 and Its Monoclonal Antibody
}

\author{
YUTAKA TAKAHASHI ${ }^{1}$, TOMOHIRO YASUI ${ }^{2}$, KAZUMASA MINAMI $^{2}$, KEISUKE TAMARI $^{1}$, \\ KEISUKE OTANI $^{1}$, YUJI SEO ${ }^{1}$, FUMIAKI ISOHASHI ${ }^{1}$, MASAHIKO KOIZUMI ${ }^{2}$ and KAZUHIKO OGAWA ${ }^{1}$ \\ Departments of ${ }^{1}$ Radiation Oncology, and ${ }^{2}$ Medical Physics and Engineering, \\ Osaka University Graduate School of Medicine, Suita, Japan
}

\begin{abstract}
Aim: An immunocomplex of interleukin-2 (IL-2) and its monoclonal antibody, S4B6 (IL-2/S4B6), contributes to antitumor immune systems. We investigated the antitumor efficacy of radiation (IR) combined with IL-2/S4B6 for osteosarcoma. Materials and Methods: LM8 mouse osteosarcoma cells were inoculated into both legs of $\mathrm{C} 3 \mathrm{H}$ mice. For groups treated with IL-2/S4B6 alone, and those treated with IR combined with IL-2/S4B6 (COMB), IL-2/S4B6 was intraperitoneally administered on days 12 and 16 after tumor cell inoculation. For groups treated with IR alone or $C O M B$, one side leg was irradiated at 10 Gy on day 12. Results: Although monotherapy with IL-2/S4B6 provided no significant tumor growth inhibition, combined therapy significantly reduced tumor volume in both irradiated and unirradiated tumors by $99 \%$ and $58 \%$, respectively, compared to the no-treatment group, with significant induction of $C D 8^{+}$ T-cells in unirradiated tumors. Moreover, the combination therapy significantly prolonged overall survival. Conclusion: Radiation combined with IL-2/S4B6 may be a potential therapeutic option for therapy of osteosarcoma.
\end{abstract}

Osteosarcoma is a common malignancy of bone in children and adolescents $(1,2)$. Despite recent innovations in surgical and high-precision radiation therapy techniques, control of metastasis has remained a major barrier to further improvement in clinical outcomes.

An immunomodulatory approach to osteosarcoma has been utilized, including immune checkpoint blockade and

Correspondence to: Yutaka Takahashi, Ph.D., Department of Radiation Oncology, Osaka University Graduate School of Medicine, 2-2 Yamada-oka, Suita, Osaka 565-0871, Japan. Tel: +81 668793482, Fax: +81 668793484, e-mail: ytakahashi@radonc.med.osaka-u.ac.jp

Key Words: Radiation, IL-2/S4B6, osteosarcoma, local efficacy, abscopal effect. cytokines such as interleukin 2 (IL-2) and interferon gamma. Specifically, IL-2 has been shown to have significant antitumor activity in many experimental tumor models $(3,4)$. IL-2, produced by activated T-cells and a subset of $\mathrm{CD} 4^{+} \mathrm{T}$ cells under normal conditions, activates cytotoxic T-cells as well as natural killer cells and B-cells, leading to a positive contribution to antitumor effects (5-7). CD4 ${ }^{+} \mathrm{T}$-cells also express IL-2 receptor-alpha (CD25), resulting in the activation of $\mathrm{CD} 4{ }^{+} \mathrm{CD} 25^{+}$regulatory T-cells (Tregs), that negatively contribute to antitumor immunity (6). Furthermore, because of the higher consumption of IL-2 by Tregs, the cytotoxic activity of cytotoxic T-cells is reduced (7), which is a significant disadvantage of IL-2 therapy in patients with cancer.

Recently, several groups demonstrated that a complex of IL-2 and its specific monoclonal antibody S4B6 enhanced antitumor efficacy or biological activity in vivo (7-10). A structural and biochemical characteristic study revealed that S4B6 sterically blocks IL-2-IL-2 receptor- $\alpha$ (IL-2R $\alpha$ ) interaction and enhances IL-2-IL-2R $\beta$ interaction (11-13). Because Tregs express IL-2R $\alpha$, IL-2/S4B6 immunocomplex plays a role in blocking Treg activity while stimulating all IL-2-related immune cells, particularly cells with high expression of IL-2R $\beta$ (11).

Radiation therapy has been recognized as a major therapeutic strategy for localized tumors. In addition to the contribution of radiation therapy to the local effect, several studies demonstrated that radiation therapy enhances the immune response, as evidenced not only by the regression of local tumors at irradiated sites but also by the regression of metastatic tumors outside the radiation field (14-17). This phenomenon is called the abscopal effect, but is rarely seen in preclinical models and clinical practice. Increasing evidence suggests that radiation itself enhances the immune system by various mechanisms. For example, radiation enhances the efficacy of immune checkpoint blockade therapy, suggesting that radiation may contribute to an 
enhanced immune response (18-22). To the best of our knowledge, however, the combined effect of radiation with IL-2/S4B6 against osteosarcoma has not been investigated.

Here, we evaluated the contribution of radiation to enhancing the antitumor effect of IL-2/S4B6 in terms of both local and distant antitumor efficacy.

\section{Materials and Methods}

Cell lines. LM8 mouse osteosarcoma cell line was purchased from RIKEN (Saitama, Japan). This cell line underwent microbiological examination in June 2015 for the presence of mycoplasma using a polymerase chain reaction test at the Monitoring Center of the Central Institute for Experimental Animals in Kanagawa, Japan, and was found to be free of contamination. The cells were maintained in Dulbecco's modified Eagle's medium supplemented with $10 \%$ fetal bovine serum, $5 \mathrm{mM}$ penicillin/streptomycin, and L-glutamine at $37^{\circ} \mathrm{C}$ in an atmosphere with $5 \% \quad \mathrm{CO}_{2}$ in an incubator.

Mouse experiments. Seven-to-eight-week-old C3H/HeNJcl mice were purchased from Nihon-Clea (Tokyo, Japan) and maintained in a specific pathogen-free area at Osaka University. All experiments were approved by the Osaka University Institutional Animal Care and Use Committee (Approval Number; 27-005-010).

The experimental schedule is shown in Figure 1a. Firstly, $3 \times 10^{5}$ LM8 cells were inoculated into both hind legs of all $\mathrm{C} 3 \mathrm{H}$ mice $(n=54)$. We then randomly assigned the mice to four treatment groups: an untreated group (no therapy group); a group receiving IL-2/S4B6 on days 12 and 15 (IL-2/S4B6 group); a group receiving $\mathrm{X}$-ray irradiation to a tumor on one leg on day 12 (radiation-only group); and a combination group receiving IL-2/S4B6 and X-ray irradiation to a tumor on one leg (combination group).

An immunocomplex of IL-2 and its monoclonal antibody S4B6 was synthesized as described previously (23). Briefly, recombinant IL-2 and S4B6 were mixed at a molar ratio of 2:1 in phosphatebuffered saline, and the mixture was incubated at $4{ }^{\circ} \mathrm{C}$ overnight.

For the IL-2/S4B 6 and combination groups, IL-2/S4B6 was given by intraperitoneal injection at $100 \mu \mathrm{g}$ on days 12 and 16 after tumor inoculation. For the radiation-alone and combination groups, mice were anesthetized with $30 \mathrm{mg} / \mathrm{kg}$ of pentobarbital by intraperitoneal injection and fixed on an in-house immobilization device. As shown in Figure 1b, on day 12, while the rest of the mouse's body was protected with lead blocks, one leg of the mouse was irradiated with $10 \mathrm{~Gy} \mathrm{X}$-ray beam using an orthovoltage X-ray irradiator (Rigaku Denki, Tokyo, Japan) $(180 \mathrm{kVp}, 15 \mathrm{~mA}$ with a $1 \mathrm{~mm} \mathrm{Al} \mathrm{filter)} \mathrm{at} \mathrm{the} \mathrm{animal} \mathrm{experiment} \mathrm{institution} \mathrm{of} \mathrm{Osaka}$ University. The thickness of the lead shields over the irradiated mice was determined by radiation dose measurements using Gafchromic EBT3 films (Ashland, KY, USA) to reduce the dose to $\leq 5 \%$ of the prescribed dose.

Tumor volume was measured at least every 3 days using the formula $L \times W \times 0.52$, where $L$ and $W$ represent the longest and the perpendicular dimensions of the tumor, respectively.

Flow cytometry. We analyzed CD8 and Tregs in tumor-infiltrating lymphocytes (TILs) in unirradiated tumors on day 19 after inoculation. Surgically removed tumors were minced in Hanks' balanced salt solution (HBSS) supplemented with $1 \%$ bovine serum albumin (BSA) and single-cell suspensions were prepared as described previously (24). Briefly, the minced tumors were incubated in HBSS supplemented with $0.5 \mathrm{mg} / \mathrm{ml}$ of collagenase IV (Sigma Aldrich; Tokyo, Japan), $200 \mu \mathrm{g} / \mathrm{ml}$ of DNase (Sigma Aldrich) and $1 \% \mathrm{BSA}$ at $37^{\circ} \mathrm{C}$ on a shaker for $90 \mathrm{~min}$ (24). Antimouse CD16/32 antibody (Biolegend, San Diego, CA, USA) was added as the $\mathrm{Fc}$ receptor inhibitor for $10 \mathrm{~min}$ at room temperature before reaction with CD8 or CD4 antibodies. Anti-mouse rat CD8allophycocyanin (APC) antibody (Clone 53-6.7; eBioscience, San Diego, CA, USA), anti-mouse rat CD4-APC (Clone RM4-5; eBioscience) antibody, and anti-mouse rat FOXP3-Phycoerythrin (PE) (Clone FJK-16s; eBioscience) antibody were used. For forkhead box protein P3 (FOXP3) expression analysis, a FOXP3/Transcription Factor Staining Buffer Set (eBioscience) was used. All procedures on sample preparations were performed according to the manufacturer's instructions.

The stained cells were analyzed with a FACS Verse ${ }^{\mathrm{TM}}$ (Becton Dickinson, Franklin Lakes, NJ, USA). Analysis was performed using FlowJo ver. 10 (Tommy Digital Biology, Tokyo, Japan), and the percentage of CD8 TILs or Tregs $\left(\mathrm{CD}^{+}{ }^{+}\right.$and FOXP3 $\left.{ }^{+}\right)(20,25)$ was calculated.

Statistical analysis. Irradiated tumors in the RAD and COMB groups were compared using the two-tail Student $t$-test. Tumor volumes of the unirradiated tumors in the different groups were compared using Tukey's honestly significant difference test. Survival was analyzed using Kaplan-Meier survival analysis with the log-rank test. $p$ Values were adjusted based on Bonferroni correction.

\section{Results}

Combination therapy showed enhanced efficacy against tumors both inside and outside the radiation field. In order to investigate the antitumor immune response to combined therapy inside and outside the radiation field, we evaluated tumor volume change over time normalized to tumor volume on day 12 , the day of initial treatment. Although mice in the no therapy group showed rapid tumor growth in tumors in both legs, a slight tumor growth delay was observed in the IL-2/S4B6-treated group (Figure 2a). As expected, X-ray irradiation strongly inhibited tumor growth in the irradiated leg but no abscopal effect was observed on the unirradiated tumors. In contrast, mice in the combination group experienced tumor volume reduction of both the irradiated and unirradiated tumors. In quantitative analysis on day 21, the volume of irradiated tumors in the combination group showed a $46 \%$ reduction compared to the radiation-only group (Figure 2b). Although no significant difference in volume was seen between unirradiated tumors in the no therapy and IL-2/S4B6 groups, a significant difference in tumor volume was seen between the no therapy and combination groups (Figure 2c), suggesting that radiation is likely to contribute to induction of the abscopal effect.

Combination therapy provided a survival benefit. In order to examine whether the abscopal effect in the combination group was reflected in a survival benefit, we further 


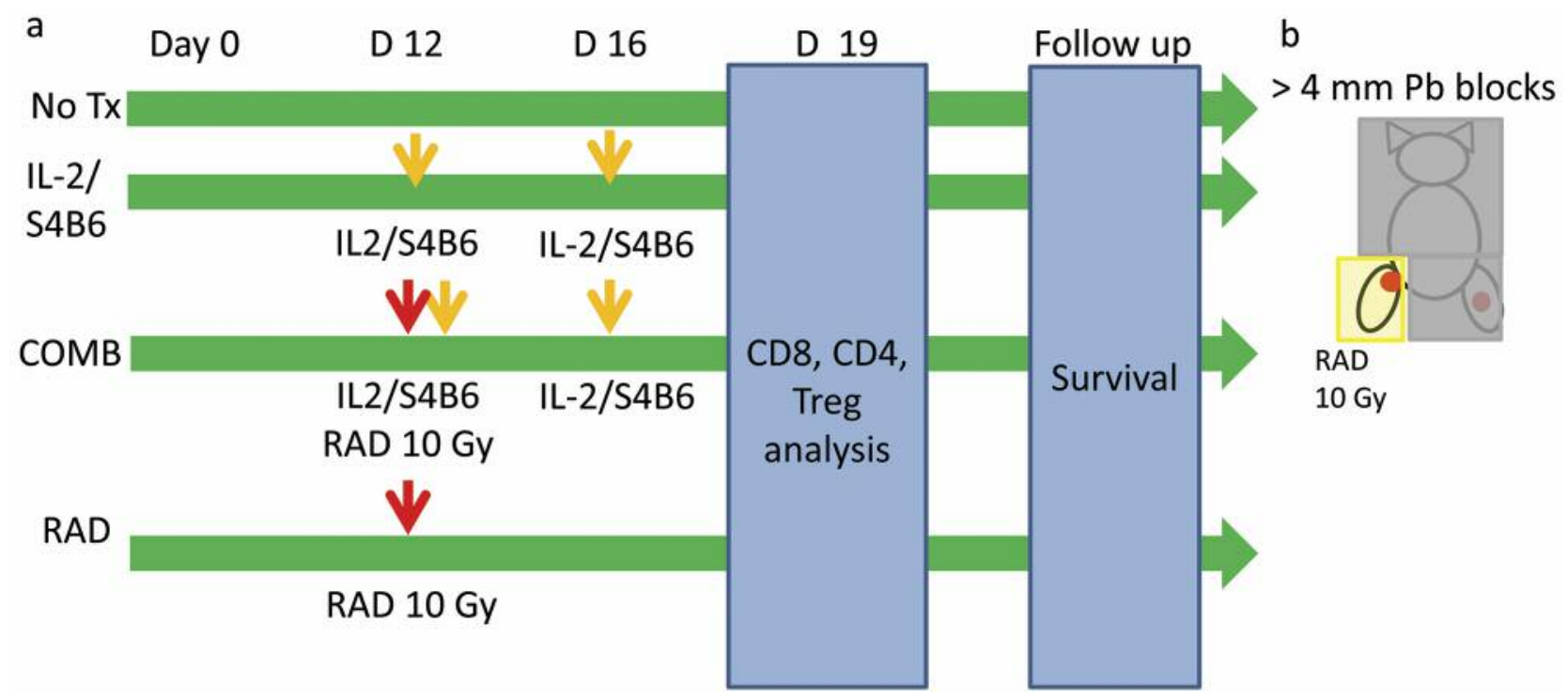

Figure 1. Experimental scheme. a: Treatment schedule and endpoints. LM8 cells were inoculated into both legs on day 0. An immune complex of interleukin-2 (IL-2) and its monoclonal antibody S4B6 (IL-2/S4B6) was intraperitoneally injected on days 12 and 16. Irradiation was performed on day 12. b: Irradiation setup. The leg of one side was irradiated, while the rest of the body was shielded with $>4 \mathrm{~mm}$ lead (Pb) blocks. No Tx: No treatment; COMB: IL-2/S4B6 with X-ray irradiation; and RAD: X-ray irradiation.
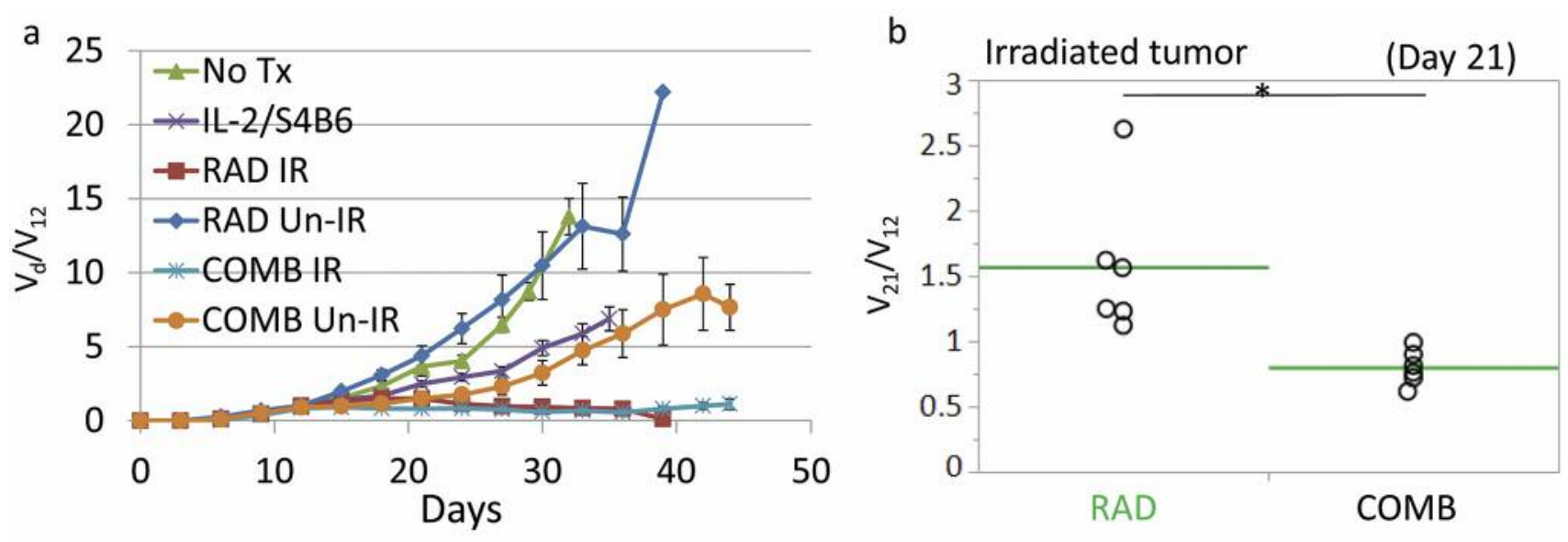

Figure 2. Effect of an immune complex of interleukin-2 (IL-2) and its monoclonal antibody S4B6 (IL-2/S4B6) with and without irradiation on tumor volume change in irradiated and unirradiated legs. a: Tumor volume change on each day normalized to that at day 12, b: Irradiated tumor volume on day 21. p-Values were determined by using two-tailed Student t-test. c: Unirradiated tumor volume on day 30. p-Values were determined using Turkey's honestly significant difference test. Bars show mean values; Significantly different at $* p<0.05$ and $* * p<0.01$. No Tx: No treatment; IL-2/S4B6: Interleukin-2 and its monoclonal antibody S4B6; COMB: IL-2/S4B6 with X-ray irradiation; RAD: X-ray irradiation; IR-leg: irradiated leg; UnIR-leg: unirradiated leg.

c

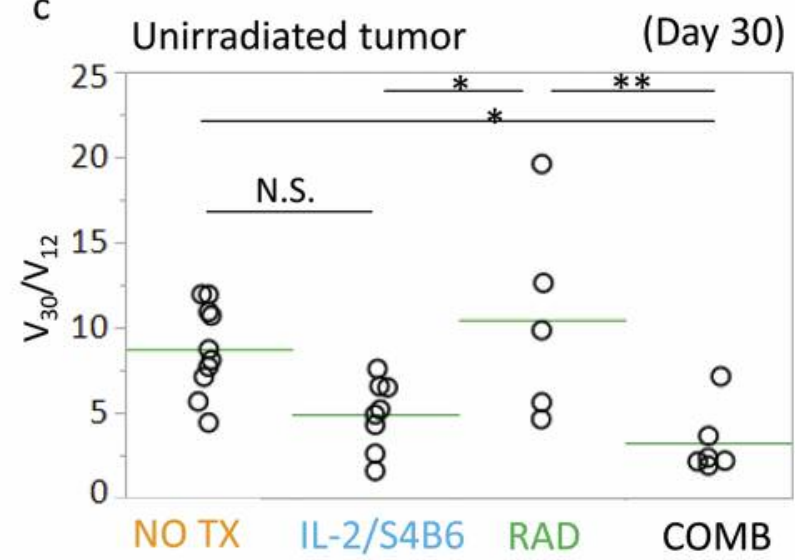




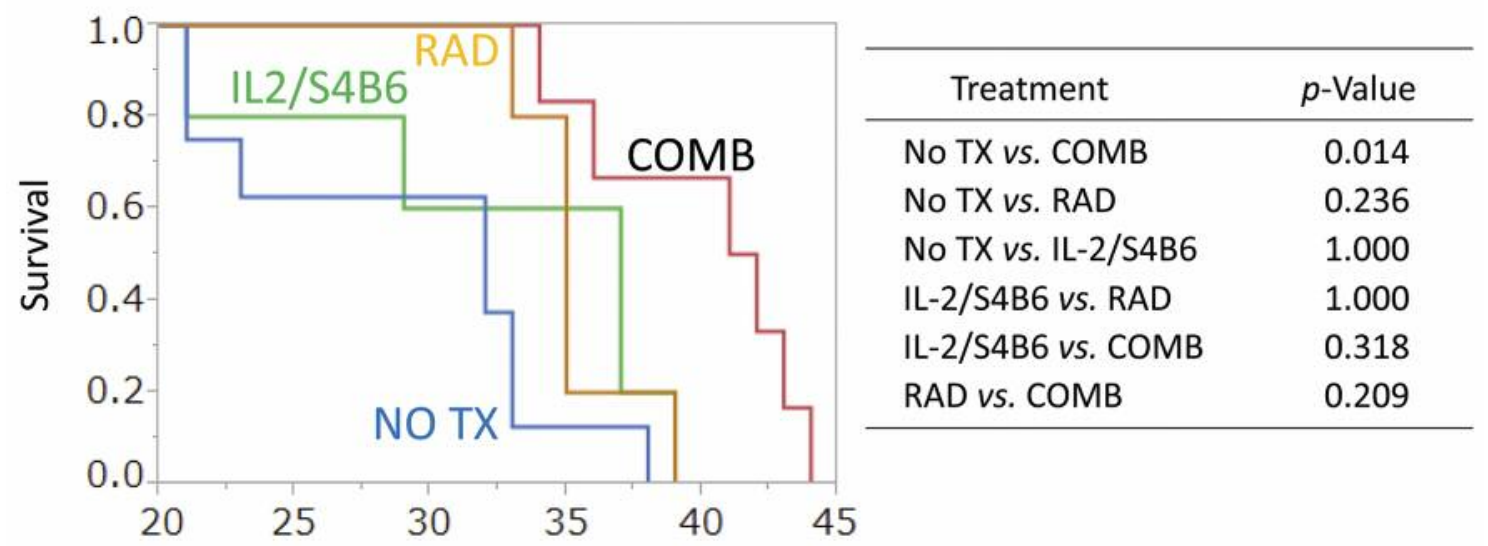

Figure 3. Effect of an immune complex of Interleukin-2 (IL-2) and its monoclonal antibody S4B6 (IL-2/S4B6) with and without X-ray irradiation on overall survival. $p$-Values were determined by log-rank test with Bonferroni correction. Overall: $p=0.0041$ (log-rank test). No Tx: No treatment; IL-2/S4B6: Interleukin-2 and its monoclonal antibody S4B6; COMB, IL-2/S4B6 with X-ray irradiation; RAD, X-ray irradiation.

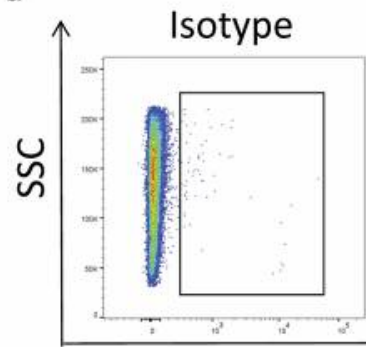

No Tx

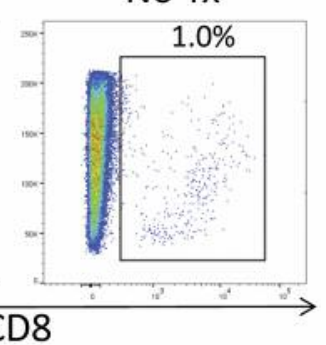

b

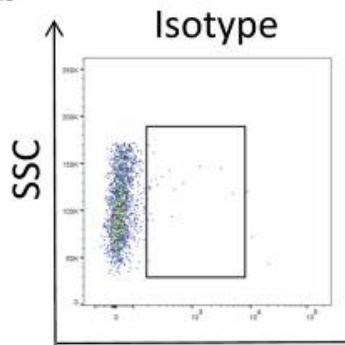

IL-2/S4B6

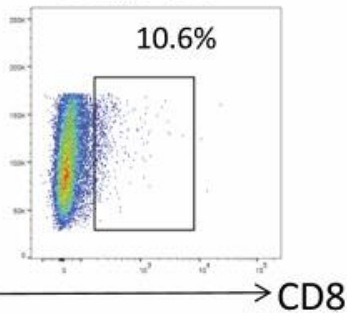

C
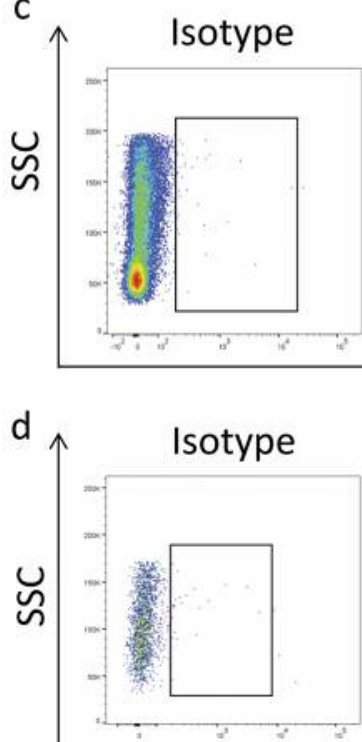

RAD IR

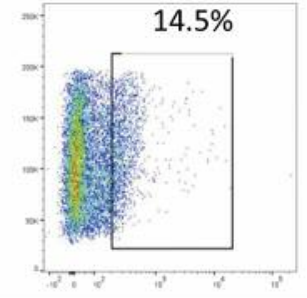

$\mathrm{CD} 8$

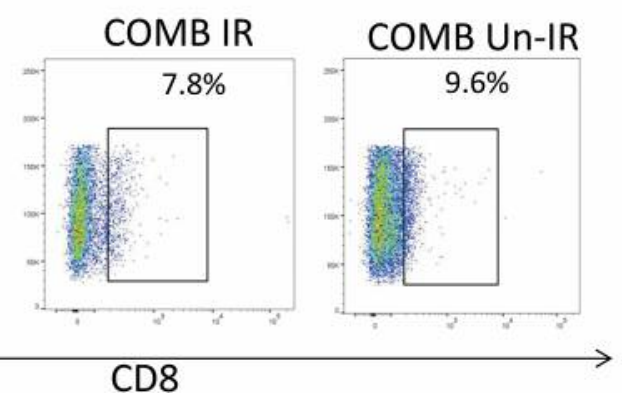

RAD Un- IR

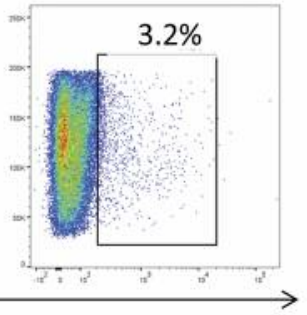

$\mathrm{e}$

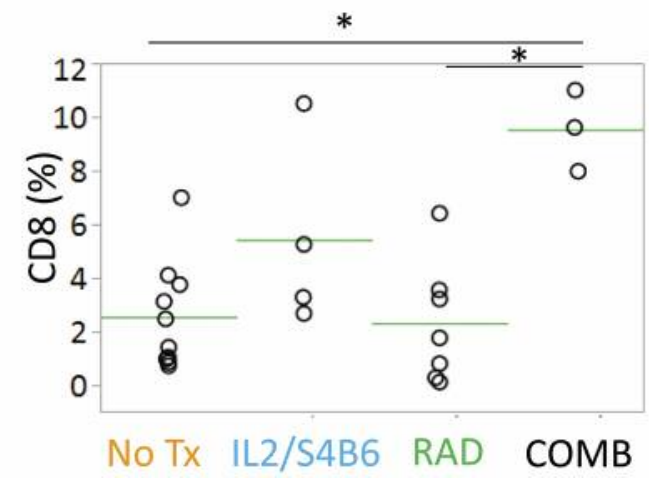

Figure 4. Changes in $C D 8^{+} T$-cells in irradiated or unirradiated tumors in mice with no therapy (No Tx) (a), interleukin-2 (IL-2)/S4B6 (b), X-ray irradiation $(R A D)(c)$, and combination of $I L-2 / S 4 B 6$ with radiation $(C O M B)(d)$. e: Quantitative data of the proportion of $C D 8^{+}$tumor-infiltrating lymphocytes. Isotype control data for the IL-2/S4B6 and COMB groups was shared because the experiment was conducted on the same day under exactly the same conditions. Bars show the mean value. p-Values were determined by the Turkey's honestly significant difference tests: *significantly different at p<0.05. IR-leg, Irradiated leg; UnIR-leg: unirradiated leg. 
a

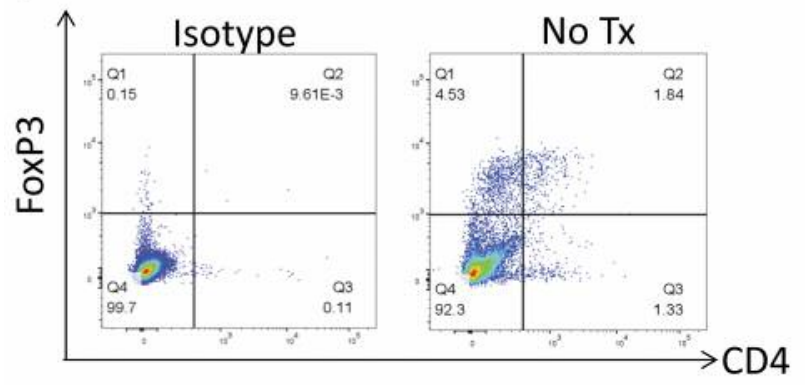

$\mathrm{b}$

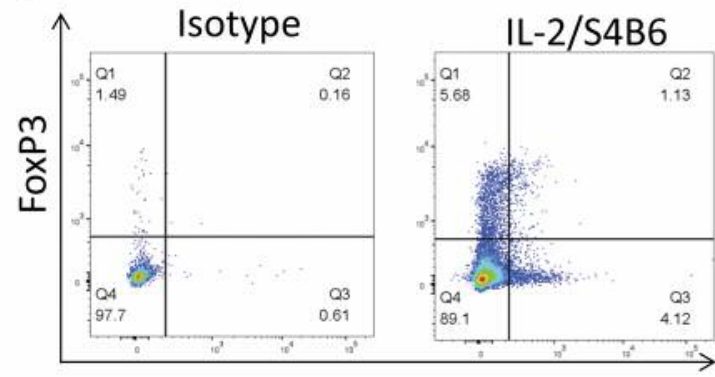

CD4

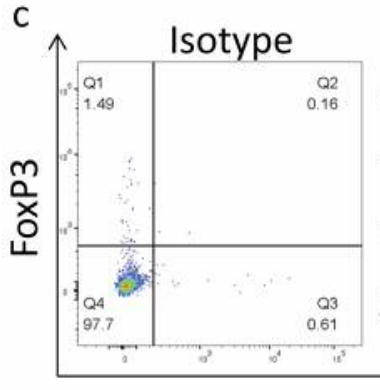

d

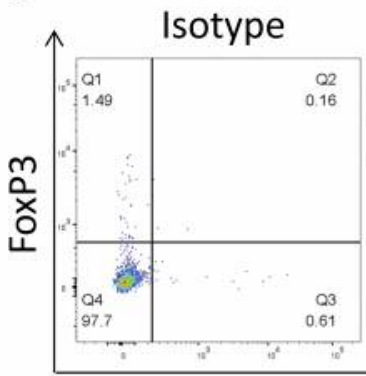

RAD IR

RAD Un- IR
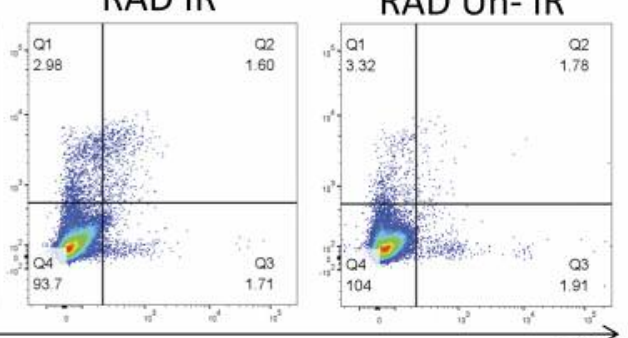

$\mathrm{e}$

Unirradiated legs

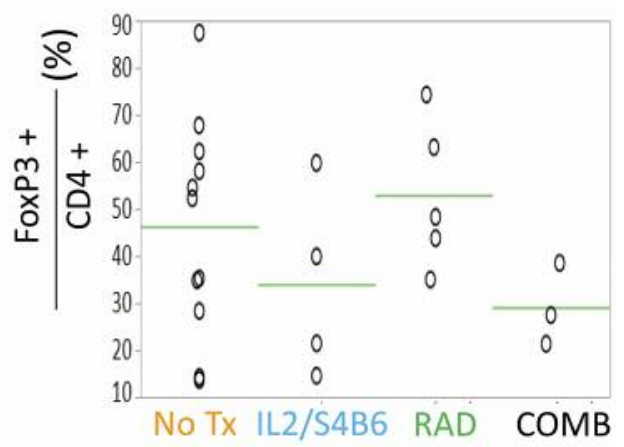

Figure 5. Changes in forkhead box protein $\mathrm{P} 3(\mathrm{FOXP} 3)^{+}$in $\mathrm{CD}^{+}$regulatory $T$-cells (Tregs) in the unirradiated tumor in in mice with no therapy $($ No $T x)(a)$, interleukin-2 (IL-2)/S4B6 (b), X-ray irradiation (RAD) (c), and combination of IL-2/S4B6 with radiation (COMB) (d).e: Quantitative data of the proportion of FOXP3+ cells in $C D 4^{+}$tumor-infiltrating lymphocytes. Isotype control data for the IL-2/S4B6, RAD, and COMB groups was shared because the experiment was conducted in the same day under the exactly same condition. No statistical significance was observed among groups. IR-leg, Irradiated leg; UnIR-leg: unirradiated leg.

observed the mice. Consistent with the change in tumor volume, only combined therapy provided a significant survival benefit (Figure 3), with median survival of 32, 37, 35 , and 42 days for mice in the no therapy, IL-2/S4B6, radiation-only, and combination groups, respectively.

Combination therapy altered immune cell distribution in the unirradiated tumors. We next examined whether tumor regression of the unirradiated tumor was associated with CD8 TILs and Tregs. Flow cytometric analysis revealed only a modest increase in $\mathrm{CD}^{+}$TILs in the IL-2/S4B6-treated mice (Figure $4 \mathrm{~b}$ ). In the group treated with radiation only, in contrast, increased recruitment of $\mathrm{CD} 8^{+}$TILs was observed in the irradiated tumor, but consistent with our finding that the abscopal effect was not seen in the group treated with radiation only, unirradiated tumors in these mice showed only a slight increase in $\mathrm{CD}^{+}$TILs (Figure 4c). Notably, however, while combination therapy also resulted in the recruitment of $\mathrm{CD}^{+}$TILs in the irradiated tumor, the same tendency was also observed in the unirradiated tumor (Figure 4d). Quantitative evaluation revealed a significant difference in $\mathrm{CD}^{+}$TILs in these unirradiated tumors between the no therapy and combination groups, but no significant difference between the no therapy and IL-2/S4B6 groups (Figure 4e).

Tregs in the IL-2/S4B6 and combination groups were slightly reduced (Figure $5 \mathrm{~b}$ and d). In contrast to CD8 ${ }^{+}$TILs, however, only a slight increase in Tregs was observed in both the irradiated and unirradiated tumors in mice treated with radiation only (Figure 5c). No significant difference in Tregs was seen among the four groups (Figure 5e). 


\section{Discussion}

IL-2 activates $\mathrm{CD} 8^{+} \mathrm{T}$-cells and a subset of $\mathrm{CD} 4^{+} \mathrm{T}$-cells and potentially contributes as a growth factor for immune cells. Indeed, previous preclinical studies $(3,4)$ and a clinical trial (5) demonstrated that IL-2 had significant antitumor effects. Due to the short half-life of IL-2, however, very high dose administration was necessary, resulting in serious toxicities $(8,26,27)$. In addition, accumulating evidence suggests that a small amount of IL-2 works as immunosuppressive rather than stimulant of $\mathrm{CD}^{+} \mathrm{T}$-cells $(26,27)$.

To overcome these problems, the biological activity and antitumor efficacy of an immunocomplex, IL-2/S4B6, has been intensively performed. Pheran et al. demonstrated that an administration of S4B6 to IL-2-injected-BALB/c mice increased IL-2 concentration by 30,000-fold after 1 day, suggesting that S4B6 dramatically increased the half-life of IL-2 (28). Consistent with their findings, other studies demonstrated prolonged stimulation and expansion of $\mathrm{CD}^{+}$ T-cells as well as an inhibitory effect on Tregs (7-9). Kamimura et al. reported that administration of IL-2 monoclonal antibody to IL-2-abundant mice showed a significant antitumor effect in a melanoma mouse model (7). Tomala et al. demonstrated that IL-2/S4B6 had considerable antitumor activity when injected early after tumor inoculation in a mouse model of BCL1 leukemia and B6-F10 melanoma (9). Meanwhile, previous reports demonstrated that radiation enhanced the immune response $(14-22,29)$. Considering these findings, we hypothesized that X-ray irradiation would enhance the antitumor efficacy of IL2/S4B6 therapy.

Firstly, we demonstrated that radiation combined with IL2/S4B6 produced a radiosensitizing effect on the irradiated tumor. Of note, this effect was seen at day 20 , which is faster than the effect seen in the group treated with radiation only (Figure $2 \mathrm{~b}$ ). Secondly, combination therapy provided a significant delay in tumor growth, even in unirradiated tumors. This faster and more prolonged regression of both irradiated and unirradiated tumors than in the IL-2/S4B6 group lead to the prolongation of overall survival. Thirdly, we found a higher accumulation of $\mathrm{CD}^{+} \mathrm{T}$-cells in unirradiated tumors in the combination group than in the no therapy group without affecting the proportion of $\mathrm{CD}^{+}{ }^{+} \mathrm{FOXP}^{+}{ }^{+}$Tregs, which might be associated with antitumor efficacy. To our knowledge, our present data provide the first direct evidence to show that radiation contributes to distant efficacy in IL-2/S4B6 therapy of osteosarcoma, leading to a significant survival benefit.

Localized radiation modifies the microenvironment for the secretion of cytokines and chemokines, including interferon- $\gamma$ and CXC chemokine ligand 16. This modification in turn results in increased trafficking and retention of T-cells within tumors $(14,30-33)$. Meanwhile, several groups have demonstrated that radiation enhances Treg expansion and activation (34-36), indicating that targeting Tregs in radiation therapy may further enhance immunity. Indeed, Son et al . combined radiation with Treg depletion using an antibody to CD25 and demonstrated that this enhanced radiation-mediated antitumor immunity, leading to prolonged overall survival. Given that IL-2/S4B6 immunocomplex stimulates CD8 ${ }^{+}$ T-cells but only moderately stimulates Tregs (8), the combination of radiation with IL-2/S4B6 might be an attractive treatment option. Kamimura et al. demonstrated that the use of IL-2 monoclonal antibody reduced the population of FOXP3 ${ }^{+}$ regulatory $\mathrm{CD}^{+}{ }^{+}$T-cells unless IL-2 was overexpressed. Similarly to their findings, we showed here that the use of IL-2/S4B6 with radiation increased $\mathrm{CD}^{+}$T-cells in unirradiated tumors with no increase in $\mathrm{CD}^{+}{ }^{+} \mathrm{FOXP}^{+}$Tregs. These alterations in immune cells may be associated with the antitumor activity against unirradiated tumors in combination therapy. Further evaluation of this mechanism is warranted.

In summary, we demonstrated that radiation combined with IL-2/S4B6 provided a radiosensitizing effect against irradiated tumors as well as induction of the absocopal effect, leading to prolonged overall survival in mice with osteosarcoma. Although combination therapy of radiation with immune checkpoint blockade has been intensively evaluated (18-21), our study opens the door to the study of combined therapy of radiation with IL-2/S4B6.

\section{Competing Interests}

The Authors have nothing to disclose.

\section{Acknowledgements}

This work was supported by a grant in aid from the Japanese Society of Promotion of Sciences (Kiban C: 16K07173 and Kiban B: 26290055).

\section{References}

1 Liao W, Lin JX and Leonard WJ: Interleukin-2 at the crossroads of effector responses, tolerance and immunotherapy. Immunity 38(1): 13-25, 2013.

2 D'Angelo SP, Tap WD, Schwartz GK and Carvajal RD: Sarcoma immunotherapy: past approaches and future directions. Sarcoma 14: 1-13, 2014

3 Waldmann TA: The biology of interleukin-2 and interleukin-15: implications for cancer therapy and vaccine design. Nat Rev Immunol 6: 595-601, 2006.

4 Oppenheim MH and Lotze MT: Interleukin-2: solid-tumor therapy. Oncology 51: 154-169, 1994.

5 Gaffen SL and Liu KD: Overview of interleukin-2 function, production and clinical applications. Cytokine 28: 109-123, 2004.

6 Setoguchi R, Hor S, Takahashi T and Sakaguchi S: Homeostatic maintenance of natural $\mathrm{FOXP} 3+\mathrm{CD} 25+\mathrm{CD} 4+$ regulatory T-cells by interleukin (IL)-2 and induction of autoimmune disease by IL-2 neutralization. J Exp Med 201(5): 723-735, 2005. 
7 Kamimura D, Sawa Y, Sato M, Agung E, Hirano $T$ and Murakami M: IL-2 in vivo activities and antitumor efficacy enhanced by an anti-IL-2 mAb. J Immunol 177(1): 306-314, 2006.

8 Tomala J, Chmelova H, Strohalm J, Ulbrich K, Sirova M, Rihova B and Kovar M: Antitumor activity of IL-2/anti-IL-2 $\mathrm{mAb}$ immunocomplexes exerts synergism with that of $\mathrm{N}-(2-$ hydroxypropyl) methacrylamide copolymer-bound doxorubicin conjugate due to its low immunosuppressive activity. Int $\mathbf{J}$ Cancer 129(8): 2002-2012, 2011.

9 Tomala J, Chmelova H, Mrkvan T, Rihova B and Kovar M: In vivo expansion of activated naive $\mathrm{CD} 8^{+} \mathrm{T}$-cells and $\mathrm{NK}$ cells driven by complexes of IL-2 and anti-IL-2 monoclonal antibody as novel approach of cancer immunotherapy. J Immunol 183(8): 4904-4912, 2009.

10 Verdeil G, Marquardt K, Surh CD and Sherman LA: Adjuvants targeting innate and adaptive immunity synergize to enhance tumor immunotherapy. Proc Natl Acad Sci USA 105(43): 1668316688, 2008.

11 Malek TR and Bayer AL: Tolerance, not immunity, crucially depends on IL-2. Nat Rev Immunol 4: 665-674, 2004.

12 Boyman O, Kovar M, Rubinstein MP, Surh CD and Sprent J: Selective stimulation of T-cell subsets with antibody-cytokine immune complexes. Science 311(5769): 1924-1927, 2006.

13 Spangler JB, Tomala J, Luca VC, Jude KM, Dong S, Ring AM, Votavova P, Pepper M, Kovar M and Garcia KC: Antibodies to interleukin-2 elicit selective T-cell subset potentiation through distinct conformational mechanisms. Immunity 42(5): 815-825, 2015.

14 Park B, Yee C and Lee KM: The effect of radiation on the immune response to cancers. Int J Mol Sci 15(1): 927-943, 2014

15 Ohba K, Omagari K, Nakamura T, Ikuno N, Saeki S, Matsuo I, Kinoshita H, Masuda J, Hazama H,Sakamoto I and Kohno S: Abscopal regression of hepatocellular carcinoma after radiotherapy for bone metastasis. Gut 43(4): 575-577, 1998

16 Burnette BC, Liang H, Lee Y, Chlewicki L, Khodarev NN, Weichselbaum RR, Fu YX and Auh SL: The efficacy of radiotherapy relies upon induction of type I interferon-dependent innate and adaptive immunity. Cancer Res 71(7): 2488-2496, 2011

17 Shiraishi K, Ishiwata Y, Nakagawa K, Yokochi S, Taruki C, Akuta T, Ohtomo K, Matsushima K, Tamatani T and Kanegasaki $\mathrm{S}$ : Enhancement of antitumor radiation efficacy and consistent induction of the abscopal effect in mice by ECI301, an active variant of macrophage inflammatory protein-1 $\alpha$. Clin Cancer Res 14(4): 1159-1166, 2008.

18 Dewan MZ, Galloway AE, Kawashima N, Dewyngaert JK, Babb JS, Formenti SC and Demaria S: Fractionated but not singledose radiotherapy induces an immune-mediated abscopal effect when combined with anti-CTLA-4 antibody. Clin Cancer Res 15(17): 5379-5388, 2009.

19 Deng L, Liang H, Burnette B, Beckett M, Darga T, Weichselbaum RR and Fu YX: Irradiation and anti-PD-L1 treatment synergistically promote antitumor immunity in mice. J Clin Invest 124(2): 687-695, 2014.

20 Twyman-Saint Victor C, Rech AJ, Maity A, Rengan R, Pauken KE, Stelekati E, Benci JL, Xu B, Dada H, Odorizzi PM, Herati RS, Mansfield KD, Patsch D, Amaravadi RK, Schuchter LM, Ishwaran H, Mick R, Pryma DA, Xu X, Feldman MD, Gangadhar TC, Hahn SM, Wherry EJ, Vonderheide RH and
Minn AJ: Radiation and dual checkpoint blockade activate nonredundant immune mechanisms in cancer. Nature 520: 373-377, 2015.

21 Kim JE, Patel MA, Mangraviti A, Kim ES, Theodros D, Velarde E, Liu A, Sankey EW, Tam A, Xu H, Mathios D, Jackson CM, Harris-Bookman S, Garzon-Muvdi T, Sheu M, Martin AM, Tyler BM, Tran PT, Ye X, Olivi A, Taube JM, Burger PC, Drake CG, Brem H, Pardoll DM and Lim M: Combination therapy with anti-PD-1, anti-TIM-3 and focal radiation results in regression of murine gliomas. Clin Cancer Res 23(1): 124-136, 2017.

22 Yoshimoto Y, Suzuki Y, Mimura K ando K, Oike T, Sato H, Okonogi N, Maruyama T, Izawa S, Noda S, Fujii H, Kono K and Nakano T: Radiotherapy-induced anti-tumor immunity contributes to the therapeutic efficacy of irradiation and can be augmented by CTLA-4 blockade in a mouse model. PloS one 9(3): e92572, 2014.

23 Webster KE, Walters S, Kohler RE, Mrkvan T, Boyman O, Surh $\mathrm{CD}$, Grey ST and Sprent J: In vivo expansion of T-reg cells with IL-2-mAb complexes: induction of resistance to EAE and longterm acceptance of islet allografts without immunosuppression. J Exp Med 206(4): 751-760, 2009.

24 Ruiz VE, Sachdev M, Zhang S, Wen S and Moss SF: Isolating, immunophenotyping and ex vivo stimulation of $\mathrm{CD}^{+}$and $\mathrm{CD}^{+}$ gastric lymphocytes during murine Helicobacter pylori infection. J Immunol Methods 384(1): 157-163, 2012.

25 Koyama S, Akbay EA, Li YY, Herter-Sprie GS, Buczkowski KA, Richards WG, Gandhi L, Redig AJ, Rodig SJ, Asahina H, Jones RE, Kulkarni MM, Kuraguchi M, Palakurthi S, Fecci PE, Johnson BE, Janne PA, Engelman JA, Gangadharan SP, Costa DB, Freeman GJ, Bueno R and Hodi FS: Adaptive resistance to therapeutic PD1 blockade is associated with upregulation of alternative immune checkpoints. Nat Commun 17(7): 10501, 2016.

26 Boyman O, Surh CD and Sprent J: Potential use of IL-2/anti-IL2 antibody immune complexes for the treatment of cancer and autoimmune disease. Expert Opin Biol Ther 6(12): 1323-1331, 2006.

27 Boyman $\mathrm{O}$ and Sprent J: The role of interleukin-2 during homeostasis and activation of the immune system. Nat Rev Immunol 12(3): 180, 2012.

28 Phelan JD, Orekov $\mathrm{T}$ and Finkelman FD: Cutting edge: mechanism of enhancement of in vivo cytokine effects by anticytokine monoclonal antibodies. J Immunol 180(1): 44-48, 2008.

29 Suzuki Y, Mimura K, Yoshimoto Y, Watanabe M, Ohkubo Y, Izawa $\mathrm{S}$, Murata $\mathrm{K}$, Fujii $\mathrm{H}$, Nakano $\mathrm{T}$ and Kono $\mathrm{K}$ : Immunogenic tumor cell death induced by chemoradiotherapy in patients with esophageal squamous cell carcinoma. Cancer Res 72(16): 3967-3976, 2012.

30 Matsumura S, Wang B, Kawashima N, Braunstein S, Badura M, Cameron TO, Babb JS, Schneider RJ, Formenti SC, Dustin ML and Demaria S: Radiation-induced CXCL16 release by breast cancer cells attracts effector T-cells. J Immunol 181(5): 30993107, 2008.

31 Matsumura S and Demaria S: Up-regulation of the proinflammatory chemokine CXCL16 is a common response of tumor cells to ionizing radiation. Radiat Res 173(4): 418-425, 2010.

32 Draghiciu O, Walczak M, Hoogeboom BN, Franken KL, Melief KJ, Nijman HW and Daemen T: Therapeutic immunization and local low-dose tumor irradiation, a reinforcing combination. Int J Cancer 134(4): 859-872, 2014. 
33 Lugade AA, Sorensen EW, Gerber SA, Moran JP, Frelinger JG and Lord EM: Radiation-induced IFN- $\gamma$ production within the tumor microenvironment influences antitumor immunity. J Immunol 180(5): 3132-3139, 2008.

34 Schaue D, Ratikan JA, Iwamoto KS and McBride WH: Maximizing tumor immunity with fractionated radiation. Int J Radiat Oncol Biol Phys 83(4): 1306-1310, 2012.

35 Kachikwu EL, Iwamoto KS, Liao YP, DeMarco JJ, Agazaryan N, Economou JS, McBride WH and Schaue D: Radiation enhances regulatory T-cell representation. Int J Radiat Oncol Biol Phys 81(4): 1128-1135, 2011.
36 Son CH, Bae JH, Shin DY, Lee HR, Jo WS, Yang K and Park YS: Combination effect of regulatory T-cell depletion and ionizing radiation in mouse models of lung and colon cancer. Int J Radiat Oncol Biol Phys 92(2): 390-398, 2015.

Received September 24, 2017 Revised October 14, 2017 Accepted October 19, 2017 